\title{
Uso del suelo según índice de vegetación diferenciada normalizada, mediante imágenes satelitales, tambillo-Ayacucho, 2000-2014, Perú
}

\section{Land use according to normalized differentiated vegetation index, using satellite images, tambillo-Ayacucho, 2000-2014, Peru}

DOI: $10.46932 / \mathrm{sjjdv2n3-083}$

Received in: May 1st, 2021

Accepted in: Jun 30th, 2021

Jorge Luis Lozano Rodríguez

Universidad Nacional de San Cristóbal de Huamanga, Perú.

E-mail: jorge.lozano@unsch.edu.pe

Marisol Lozano Rodríguez

Universidad Nacional de San Cristóbal de Huamanga, Perú.

E-mail: mari.lozano@unsch.edu.pe

Alessandri Canchoa Quispe

Universidad Nacional Agraria La Molina, Perú.

E-mail: canchoa@lamolina.edu.pe

Eusebio Idelmo Cisneros Tarmeño

Universidad Nacional Agraria La Molina, Perú.

E-mail: ecisneros@lamolina.edu.pe

Franklin Delio Unsihuay Tovar

Universidad Nacional Agraria La Molina, Perú.

E-mail: funsihuay@lamolina.edu.pe

Héctor Ladislao Huisacaina Soto

Universidad Nacional Agraria La Molina, Perú

E-mail: hhuisac@lamolina.edu.pe

Oscar Enrique Tang Cruz

Universidad Nacional Agraria La Molina, Perú.

E-mail: otang@lamolina.edu.pe

Juan Manuel Pesantes Rojas

Universidad Nacional Agraria La Molina, Perú.

E-mail: jmpesantes@ lamolina.edu.pe

Martín Benedicto Sandoval Casas

Universidad Nacional Agraria La Molina, Perú.

E-mail: msandoval@lamolina.edu.pe

Pablo Wenceslao Velásquez Guardia

Universidad Nacional José Faustino Sánchez Carrión, Perú.

E-mail: pvelasquez@unjfsc.edu.pe 


\title{
Hernán Oscar Cortez Gutiérrez
}

Universidad Nacional del Callao, Perú.

E-mail: piedraangular765@gmail.com

\section{Milton Milcíades Cortez Gutiérrez \\ Universidad Nacional de Trujillo \\ E-mail: mcortezgutierrez@yahoo.es}

\section{RESUMEN}

El objetivo del presente trabajo de investigación fue evaluar el impacto de uso de suelos a partir de imágenes satelitales proporcionados por el sensor MODIS (Moderate Resolution Imaging Spectroradiometer), a bordo del satélite Terra para describir y estimar según el Índice de Vegetación de Diferencia Normalizada (NDVI), el comportamiento de la cobertura vegetal. El NDVI, es un parámetro físico muy importante para estudios de cobertura vegetal. En este sentido, se ha logrado obtener 341 imágenes satelitales MODIS Terra (MOD13Q1) de la página web de la NASA (National Aeronautics and Space Administration) del periodo 2000-2014 con coordenadas geográficas de $13^{\circ} 11^{\prime} 28^{\prime \prime}$ latitud sur y 7406'30' longitud oeste del distrito de Tambillo, con las cuales se hizo un análisis multitemporal del promedio del NDVI de seis escenas durante las estaciones del año, mediante el uso del software ENVI, IDL, ArcGIS y métodos estadísticos, que permitió describir el comportamiento del área de vegetación por tipo de suelo en las estaciones de verano, otoño, invierno y primavera. Los resultados obtenidos según la variación del área de vegetación: suelo agrícola (NDVI de 0,320 a 0,379), bosques de hoja ancha y perenne (NDVI de 0,380 a 0,439) y prado andino con bosque de hoja perenne (NDVI de 0,440 a 0,500), tienen una línea de tendencia positiva, validadas y estimadas con datos de precipitación y temperatura del aire registrados por la estación meteorológica de Tambillo-Ayacucho.

Estos servirán como información para mejorar el proceso y clasificación del uso de suelos y elaborar mapas temáticos que contribuyan a la mejor toma de decisiones, según los calendarios agrícolas y forestales.

Palabras Clave: Impactos, uso del suelo, bosques, Índice de Vegetación, Diferencia Normalizada, Imágenes satelitales.

\begin{abstract}
The objective of this research work was to evaluate the impact of the use of soils from satellite images provided by the MODIS sensor (Moderate Resolution Imaging Spectroradiometer), on board the Terra satellite to describe and estimate according to the Normalized Difference Vegetation Index (NDVI), the behavior of the vegetation cover. The NDVI is a very important physical parameter for studies of plant cover. In this sense, it has been possible to obtain 341 MODIS Terra satellite images (MOD13Q1) from the NASA website (National Aeronautics and Space Administration) for the period 2000-2014 with geographic coordinates of $13^{\circ} 11^{\prime} 28$ " south latitude and $74^{\circ} 06^{\prime} 30$ " west longitude of the district of Tambillo, with which a multitemporal analysis of the average of the NDVI was made of six scenes during the seasons, through the use of software ENVI, IDL, ArcGIS and statistical methods, which allowed to describe the behavior of the vegetation area by type of soil in the summer, autumn, winter and spring seasons. The results obtained according to the variation of the vegetation area: agricultural soil (NDVI from 0,320 to 0,379), broadleaf and evergreen forests (NDVI from 0,380 to 0,439) and Andean meadow with evergreen forest (NDVI from 0,440 to 0,500), they have a positive trend line, validated and estimated with data on precipitation and air temperature recorded by the Tambillo-Ayacucho weather station.
\end{abstract}

Key words: Impacts, land use, forests, Vegetation Index, Normalized Difference, Satellite images.

\section{INTRODUCCIÓN}


El desarrollo de sistemas satelitales para el monitoreo ambiental con el uso de imágenes satelitales a través de la técnica de teledetección espacial en la evaluación del impacto de uso de suelo mediante el Índice de Vegetación de Diferencia Normalizada (NDVI) es amplia; siendo numerosos los estudios realizados a nivel internacional, nacional y regional en los últimos años, pero son escasos los trabajos orientados a resolver los problemas locales dejando muchos vacíos y limitaciones; por lo que es necesario e importante tomar en cuenta los resultados obtenidos en la presente investigación.

La vegetación, es uno de los elementos más notorios del medio físico y también más significativo debido a las múltiples relaciones que mantiene con otros elementos del medio que influye en los procesos morfo genéticos, en el modelado del relieve, en los flujos hídricos; y es uno de los elementos más diferenciadores del paisaje como indicador expresivo y nulo de las interacciones que refleja los cambios de las condiciones climáticas creando microclimas locales que constituye recursos económicos y ecológicos.

La protección del suelo es otra de las importantes funciones de la vegetación, interviniendo en la definición de sus características fisicoquímicas, y en su productividad. La vegetación protege a los animales y es un elemento principal en la estructura de su hábitat. y finalmente, tal vez la función más importante para la evolución de la vida en el planeta es y será la producción de oxígeno, permitiendo el desarrollo del metabolismo aeróbico, según (Muñoz Aguayo.,2015).

El presente trabajo de investigación se llevó a cabo en el distrito de Tambillo, valle de Muyurina, provincia de Huamanga, Perú, donde viene ocurriendo una serie de variaciones en el comportamiento dinámico espacio-temporal de la vegetación, como fuente natural de recursos agrícolas y pecuarias, principal sustento económico familiar y comunal, influenciado por el incremento de la población, derivándose ello en un aumento en la demanda de alimentos, por lo que la aplicación de sistemas de información geográfica y teledetección espacial, constituyen herramientas importantes que permitirán la evaluación del impacto de uso de suelo según el índice de vegetación de diferencia normalizada y caracterizar el cambio y evolución de la cobertura vegetal por estaciones, según Solano y Rojas (2013).

El presente trabajo es justificado, porque en dicha zona existen recursos naturales y culturales que pueden aprovecharse para la actividad turística organizada, que no colisione con la actividad propia de los habitantes de las zonas, de tal modo que todas las actividades sociales y económicas se desarrollen de manera sostenible.

El distrito de Tambillo, en estos últimos años, tiene la necesidad de aplicar modelos de desarrollo sostenible que se enfoque en establecer políticas de ordenamiento territorial que parte de aspectos básicos como, resolver problemas críticos relacionados con la ocupación y uso agrícola del territorio, y articular a las diversas políticas sectoriales y orientar el accionar del municipio de Tambillo en el cumplimiento 
eficiente de sus funciones, para el bienestar de sus pobladores y estar en armonía con las condiciones ambientales y la seguridad física.

Según el ZEE de la región Ayacucho (2012), el 80\% de los pequeños productores del total de la población del distrito, son considerados como productores de la economía de subsistencia, donde su principal actividad es la agricultura y ganadería, es así que realizan el mal uso de la tierra y malas prácticas agrícolas, que tiene como consecuencia la desertificación y erosión de los suelos agrícolas. Frente a esta problemática del pequeño productor, el distrito de Tambillo fue intervenido por muchas instituciones generadoras de tecnología, que en su mayoría no han podido generar tecnologías adecuadas que permitan incrementar la producción y productividad de los pequeños productores. Las razones son variadas, desde la carencia de políticas institucionales y sectoriales hasta la planificación territorial, que prioricen a los pequeños productores quienes deben ser orientados de acuerdo a la aptitud de su recurso suelo.

\section{MATERIALES Y MÉTODOS}

El trabajo se desarrolló en los ámbitos del distrito de Tambillo, provincia de Huamanga, departamento de Ayacucho, Perú. Se ha obtenido y clasificado las imágenes descargadas gratuitamente al suscribirse a un servidor de imágenes del MRTWEB donde se encuentra datos del sensor MODIS, correspondiente al sector de la región de Ayacucho ubicado en el Path (orbita): 05; Row (punto): 69; Latitud: -12 a -13; Longitud: -74 a -73, desde el año 2002 al 2013; todas estas imágenes se procesaron mediante el software ENVI 4.8, obteniéndose a partir de ello las imágenes de los lugares direccionados por Google Earth. Para luego determinar la existencia o no de los humedales.

Tipo de investigación: Descriptivo

Diseño de la investigación: No experimental. Las 341 imágenes satelitales obtenidas desde el año 2000 al 2014, fueron compiladas y cortadas con el vector Tambillo para luego proceder a procesar los resultados de las imágenes del índice de vegetación de diferencia normalizada "NDVI" (Normalizad Difference Vegetation Índex) con el software ENVI y mostrar los resultados estadístico descriptivo de la evolución temporal de la variable dependiente (NDVI) y la variable independiente (uso de suelos), para luego clasificarlas por estaciones del año y tipo de cobertura vegetal, para finalmente validar los resultados 


\section{ANALISIS Y DISCUSION DE RESULTADOS}

\subsection{EVOLUCIÓN TEMPORAL DEL TIPO DE COBERTURA VEGETAL POR KM²}

se muestra que, en la estación de verano y otoño se tienen suelos con mayor vegetación, y suelos con menor vegetación en invierno y primavera.

Figura 1: Evolución temporal de tendencia positiva del NDVI por meses del año, durante el periodo 2000 al 2014

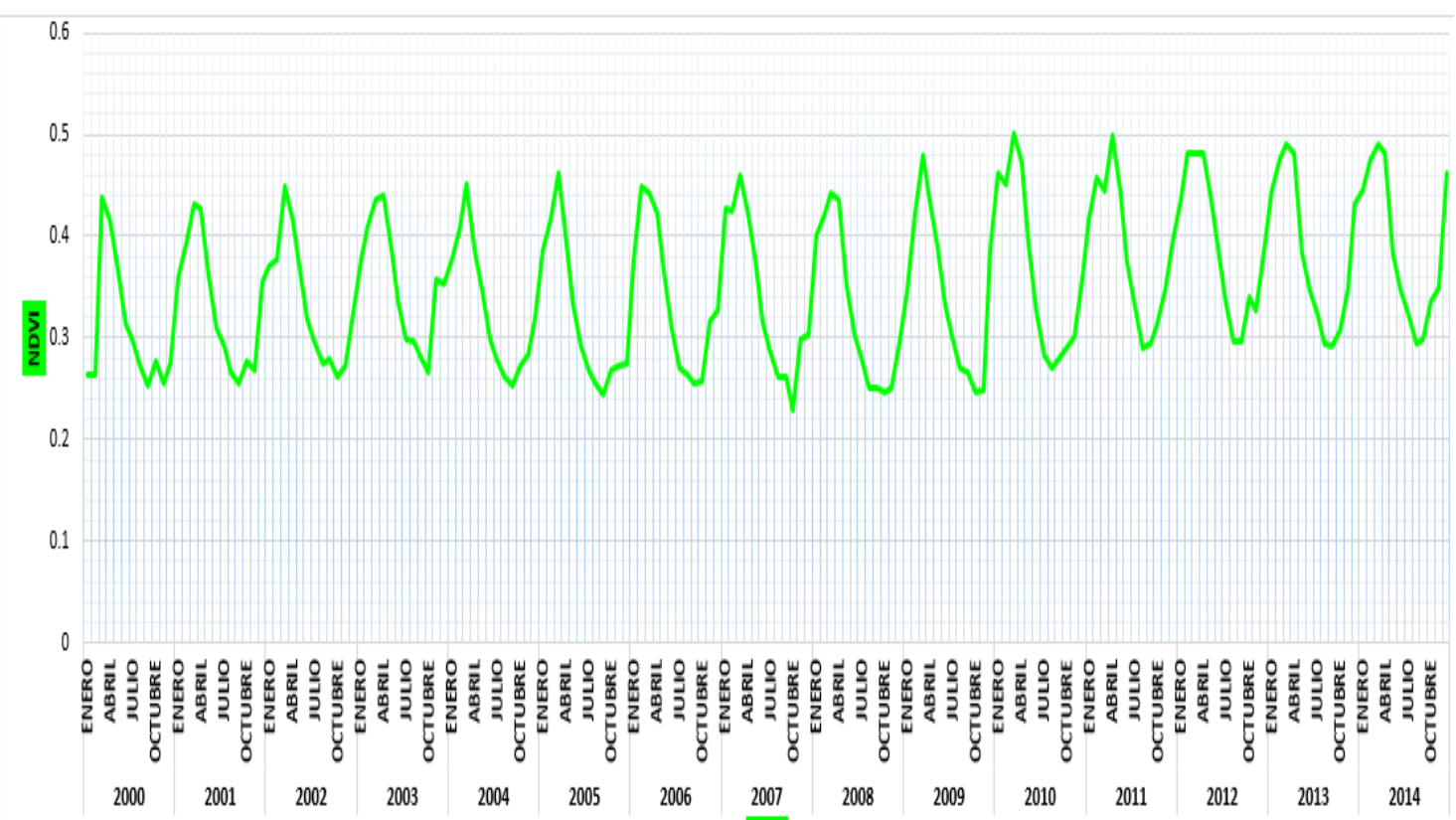

En la figura.1, se muestran los valores del NDVI por meses del año donde se observa una tendencia de crecimiento positivo llegando a un NDVI de valor más alto de 0,50119476 en el mes de marzo del 2010 y mínimo de 0,2297752 en el mes de octubre del 2007. Teniendo en cuenta que se utilizó la ecuación $2.20 \mathrm{y}$ el promedio del NDVI de dos imágenes al mes. Los meses que no hay lluvias, el NDVI es menor (escasa vegetación mes de octubre) y meses después de las lluvias el NDVI es mayor (incremento de la vegetación mes de marzo). 
Figura 2: Evolución temporal de la cobertura vegetal según el NDVI en porcentajes por estaciones del año, periodo: 2000 2014

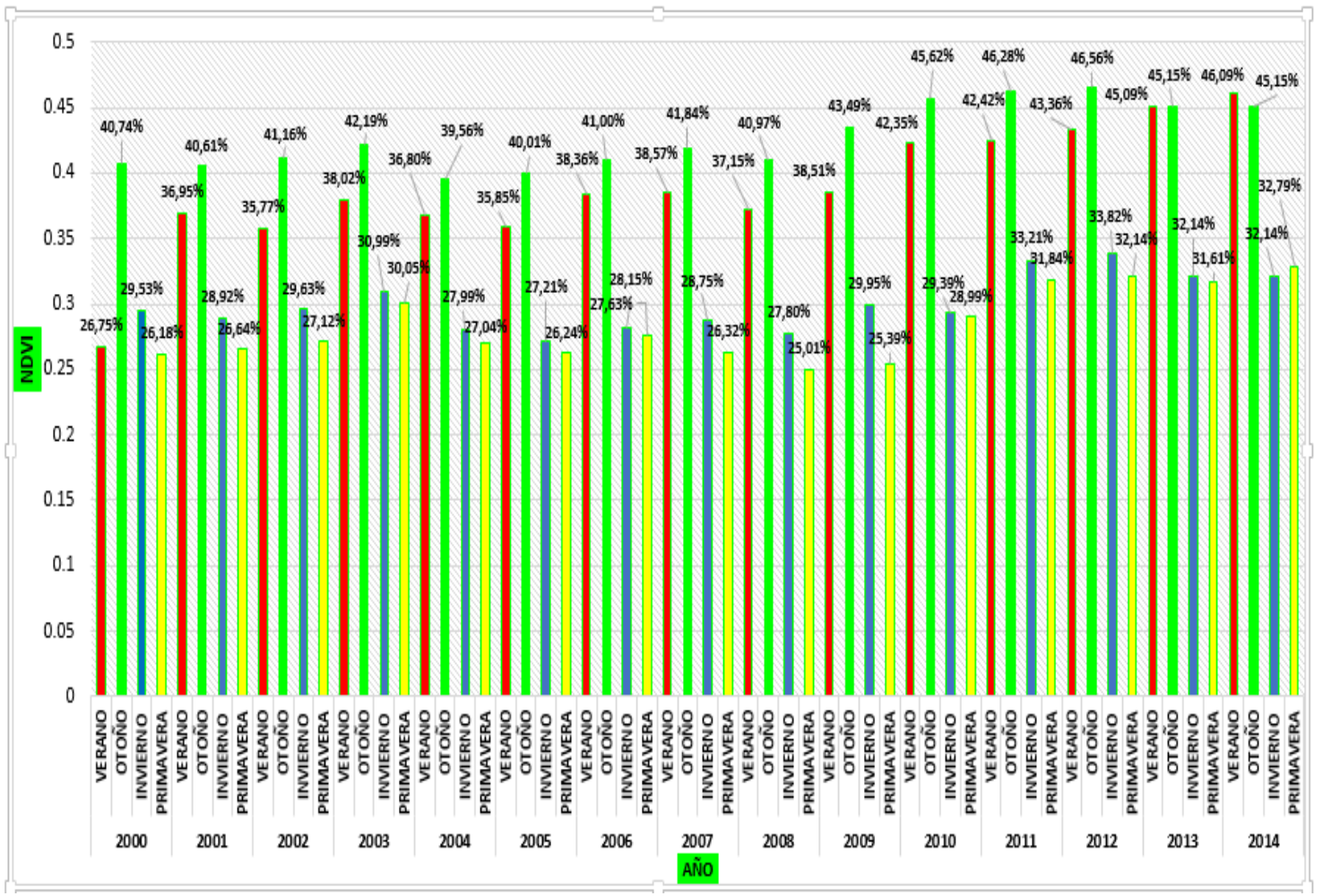

Se observa una tendencia de crecimiento positivo llegando a un NDVI de valor más alto de 0,50119476 en el mes de marzo del 2010 y mínimo de 0,2297752 en el mes de octubre del 2007

En la figura. 2, observamos los valores porcentuales del Índice de Vegetación de Diferencia Normalizada (NDVI), donde en la estación de verano se han incrementado significativamente de 26,75\% el año 2000 a 46,09\% en el año 2014. El valor del NDVI en la estación de otoño del 2000 con 40,74\%, el 2001 con 40,61\% y 42,19\% el 2003. Alcanzando un mínimo de 39,56\% el 2004, y un máximo de 46,56\% el año 2012, luego de ello descendiendo ligeramente a 45,15\% el 2013 y 2014. En invierno del 2000 al 2014 fluctuó entre 29,53\% y 32,14\% teniendo un valor mínimo el año 2005 con 27,21\% y como máximo el 2011 con 46,28\%. En la estación de primavera el NDVI mínimo se dio el año 2008 con 25,01\%, luego el 2000 con $26.18 \%$ llegando a un máximo de 32,76\% el 2014. 
Figura 3: Evolución temporal de la cobertura del tipo B (bosque seco) en $\mathrm{Km}^{2}$, periodo: 2000 - 2014

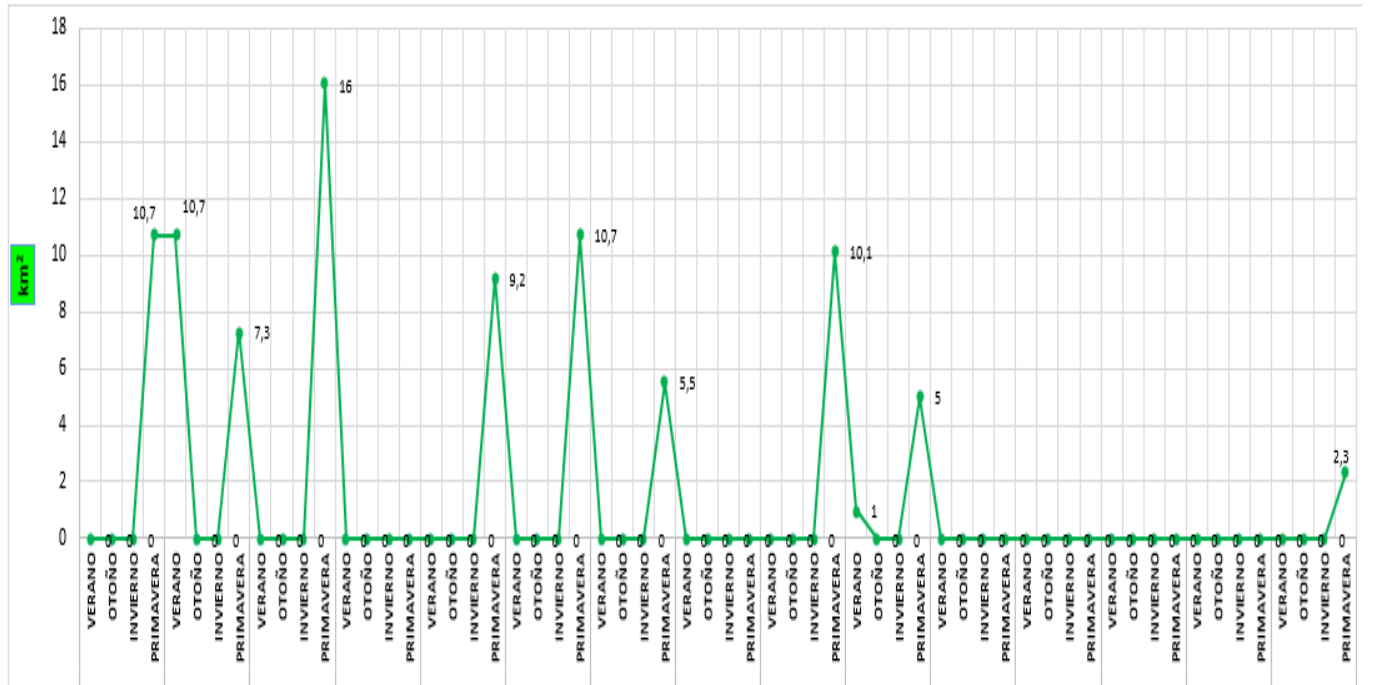

\begin{tabular}{|l|l|l|l|l|l|l|l|l|l|l|l|l|l|l|}
22000 & 2001 & 2002 & 2003 & 2004 & 2005 & 2006 & 2007 & 2008 & 2009 & 2010 & 2011 & 2012 & 2013 & 2014 \\
\hline
\end{tabular}

Se muestra que solo en la estación de primavera hubo cobertura vegetal entre el 2000 al 2009, destacando el 2002 que hubo $16 \mathrm{~km}^{2}$ de área mayor y el 2014 un área de 2,3 km².

Figura 4: Evolución temporal de tendencia negativa de la cobertura vegetal tipo C (suelo escasamente vegetado) en km² según estaciones del año en el periodo: 2000.2014

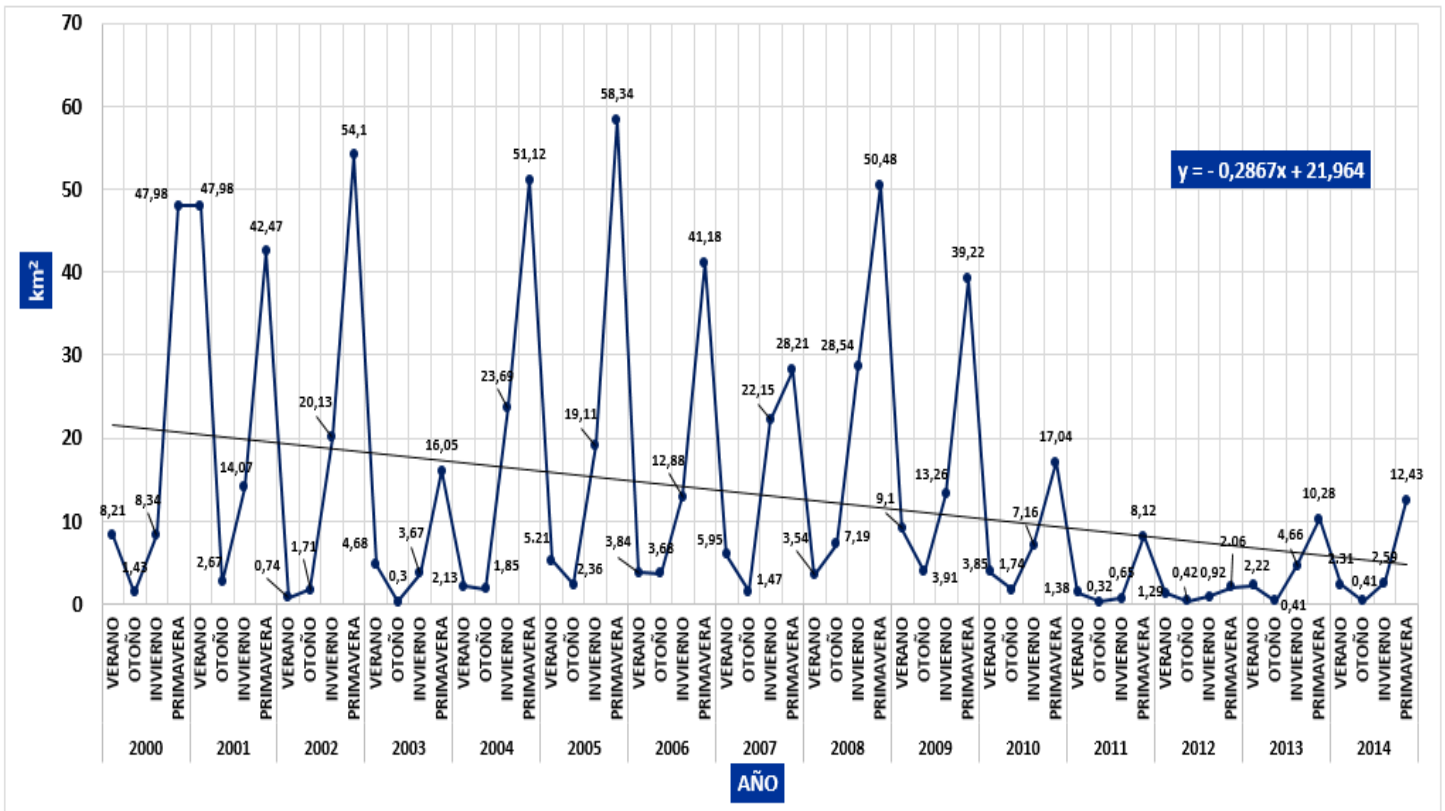

Se muestra una mayor cobertura vegetal de suelo escasamente vegetado en la estación de primavera el 2005 con $58,34 \mathrm{~km}^{2}$, luego hubo un decaimiento a $0,3 \mathrm{~km}^{2}$ en otoño del 2003 , como resultado se tiene una pendiente negativa del 2000 al 2014. 
Figura 5: Evolución temporal de tendencia negativa de la cobertura vegetal (tipo D: bosque caduco seco) en km² según estación del año, en el periodo: $2000-2014$

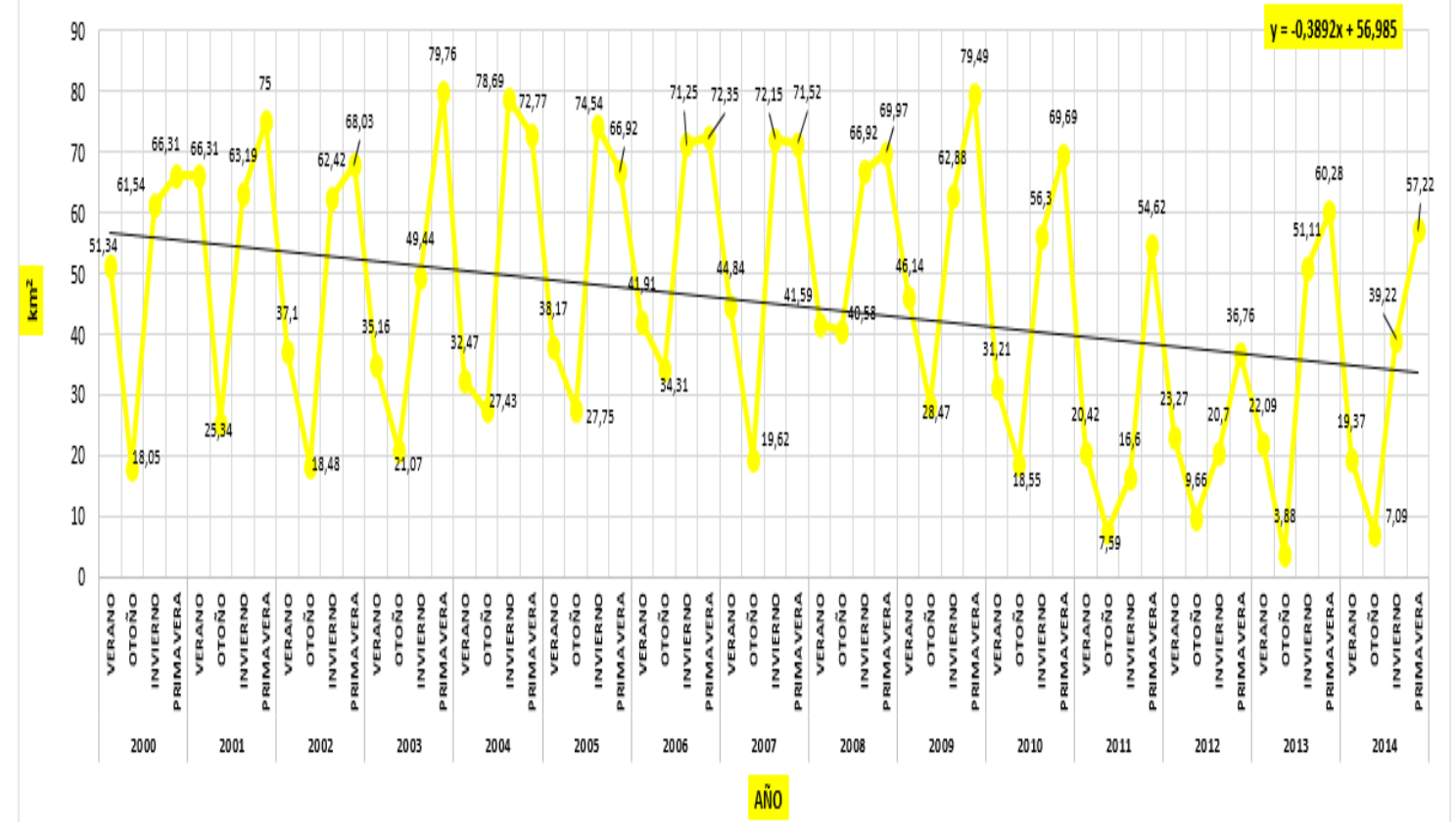

Se muestra un decaimiento de este tipo de vegetación donde en otoño del 2013 es de 3,88 km² y el mayor en primavera del 2003 de $79,76 \mathrm{~km}^{2}$.

Figura 6: Evolución temporal de tendencia positiva de la cobertura vegetal tipo E (montaña degradada de bosque caduco bajo) en $\mathrm{km}^{2}$, según estaciones del año en el periodo: 2000 - 2014

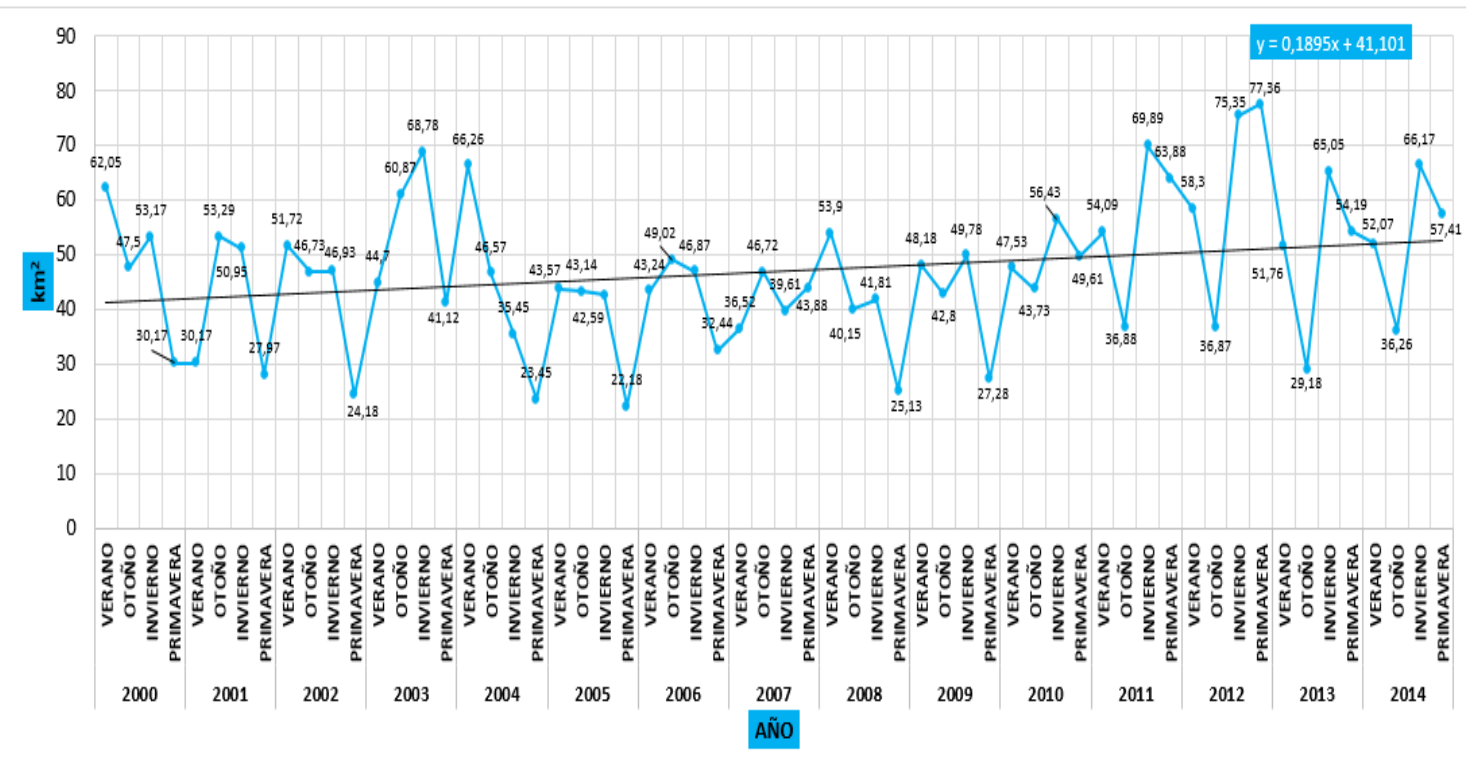

Se observa un área de vegetación menor en primavera del 2005 de $22,18 \mathrm{~km}^{2}$ y el mayor en primavera del 2012 de 77,36 km², como resultado se observa una pendiente positiva del 2000 al 2014. 
Figura 7: Evolución temporal de tendencia positiva de la cobertura vegetal tipo F (suelo agrícola) en km² según estaciones del año en el periodo: 2000 - 2014

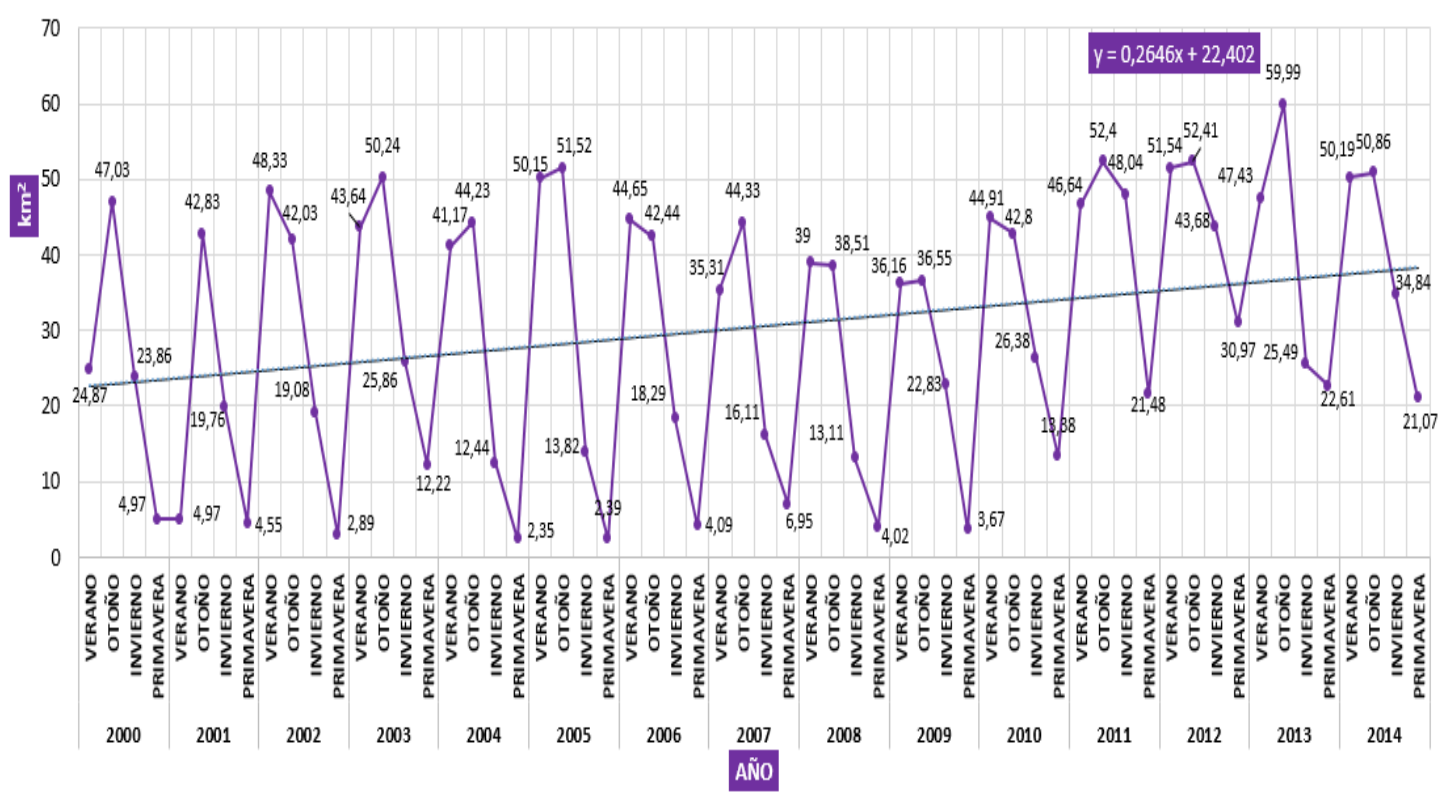

Se observa que en otoño del 2013 se tiene una mayor cobertura vegetal de suelo agricola de 59,99 y una menor cobertura de 2,35 en primavera del 2004. Este resultado afirma que aumento positivamente los suelos agricolas.

Figura 8: Evolución temporal de tendencia positiva de la cobertura vegetal tipo G (bosque de hoja ancha y perenne) en $\mathrm{km}^{2}$ según estaciones del año en el periodo: 2000 - 2014

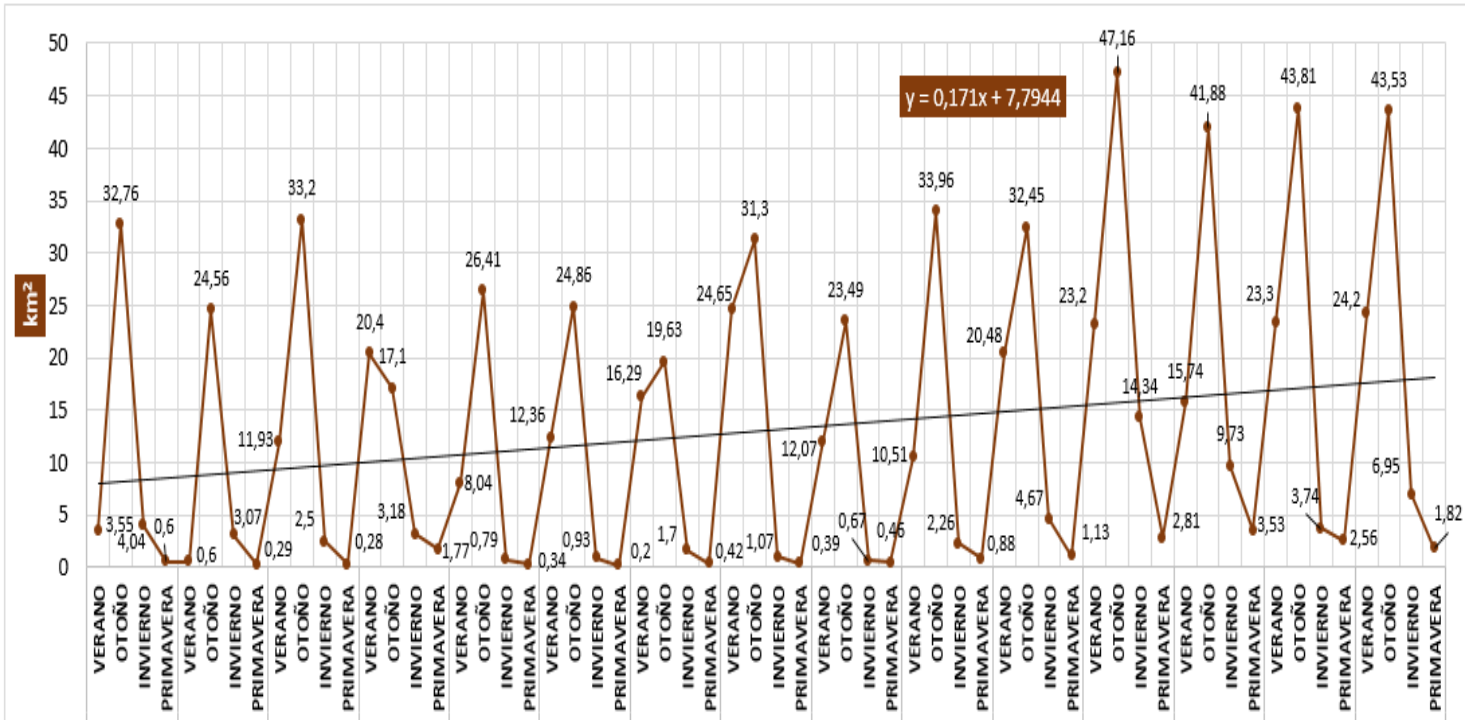

\begin{tabular}{|l|l|l|l|l|l|l|l|l|l|l|l|l|l|l|}
2000 & 2001 & 2002 & 2003 & 2004 & 2005 & 2006 & 2007 & 2008 & 2009 & 2010 & 2011 & 2012 & 2013 & 2014 \\
\hline
\end{tabular}

Muestran la información estadística donde la línea de tendencia es positiva. Pues la política institucional de la Municipalidad de Tambillo, Gobierno Regional, conjuntamente con otras instituciones 
de Ayacucho causaron directa e indirectamente el impacto positivo del uso de suelo con bosques de hojas perennes, debido la presencia de los ríos de la microcuenca de Niño Yucaes y Muyurina, y las aguas del proyecto especial del rio Cachi con lo cual tienen regadío todo el año mejorando positivamente el aumento de la vegetación en los últimos años. Observando los picos más altos en la estación de otoño representa mayor área de vegetación de bosques de hoja ancha y perenne. $(47,16$ km² el 2011) y una baja vegetación en la estación de primavera.

Figura 9: Evolución temporal de tendencia positiva de la cobertura vegetal tipo H (prado andino con bosque de hoja perenne) en $\mathrm{km}^{2}$ según estaciones del año, en el periodo: 2000 - 2014

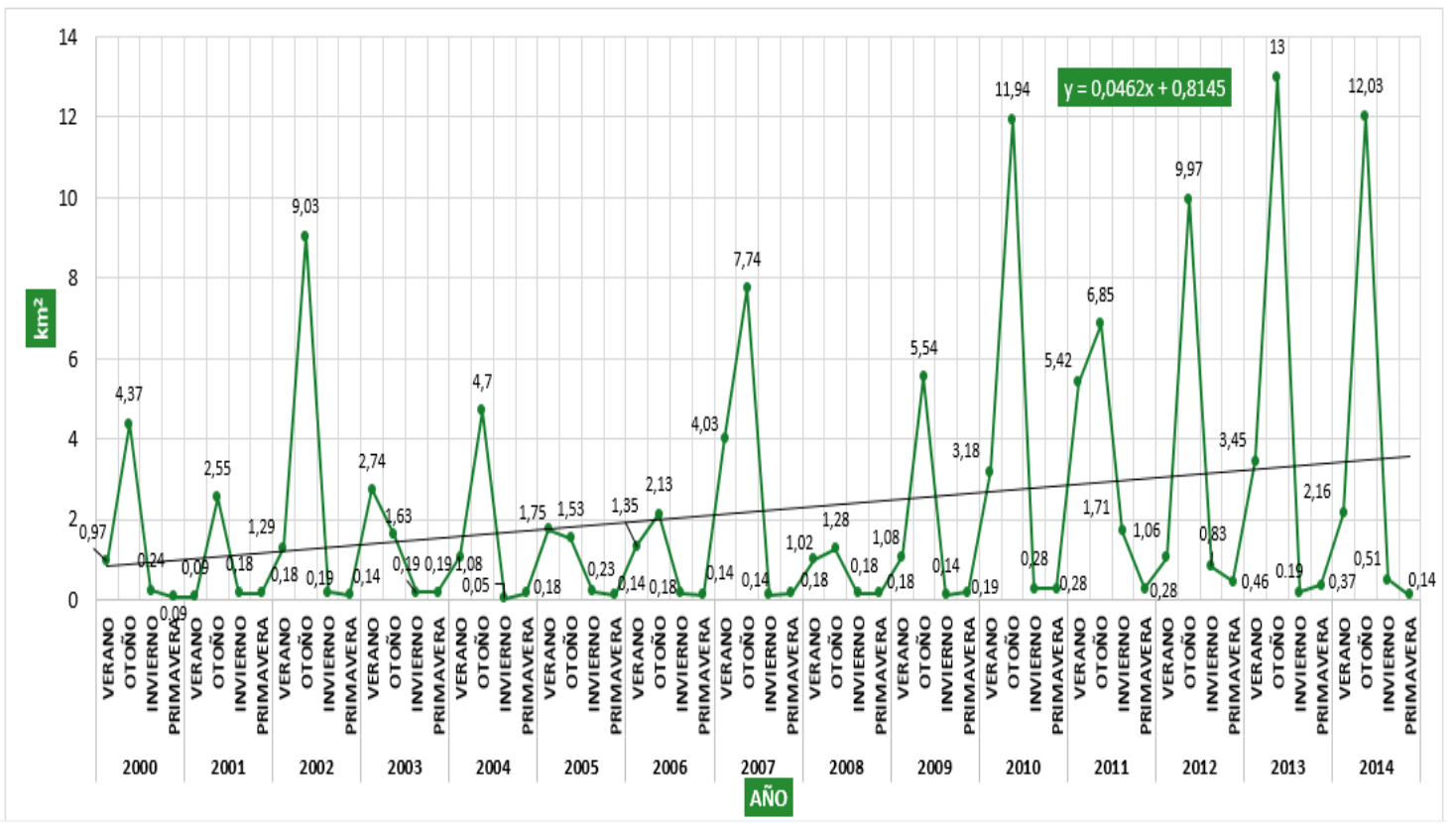

Muestra una pendiente de tendencia positiva teniendo como máxima cobertura vegetal de prado andino con bosques de hoja perenne en la estación de otoño de 2013 con 13 km² y un mínimo en la estación de invierno con $0,19 \mathrm{~km}^{2}$.

En las figuras 3 al 9 nos brindan una información acerca de la hipótesis planteada y los objetivos alcanzados donde se determinó que, en la estación de verano, (época de lluvias), la cobertura vegetal tipo D: bosque caduco seco según el NDVI 0,200 - 0,259, hubo un área de mayor extensión de 79,49 km² en el 2009, disminuyendo progresivamente el 2013 a 22,08 km². Contrariamente la cobertura vegetal tipo F: suelo agrícola según el NDVI 0,320- 0,379, tuvo un área de extensión menor de 24,87 km² en el 2008, incrementándose significativamente el 2012 a 51,54 km², teniendo una ligera disminución el 2014 a 50,19 $\mathrm{km}^{2}$. Esto nos indica que del 2000 al 2014 las áreas donde había escasa vegetación se comenzaron a incrementar significativamente.

Con respecto a la cobertura vegetal de gran vegetación en la estación de otoño, en las figuras 3 al 9 nos indican que, la cobertura vegetal tipo E: montaña degradada de bosque caduco bajo con arbustos 
caducos seco según el NDVI 0,260 - 0,319, hubo un área de extensión de 53,17 km² en el 2000, disminuyendo progresivamente el 2014 a $36,26 \mathrm{~km}^{2}$. Contrariamente la cobertura vegetal tipo F: suelo agrícola según el NDVI 0,320- 0,379 hubo un área de extensión de 47,03 km² en el 2000, incrementándose significativamente el 2014 a 50,86 $\mathrm{km}^{2}$. Otros tipos de vegetación también tiene una ligera variabilidad similar. Con este resultado se confirmó que del 2000 al 2014 las áreas donde había un bosque seco ralo de superficies disecadas se comenzaron a incrementar la vegetación significativamente.

En la estación de invierno (época de escases de lluvias), se observa en las figuras 3 al 9 la cobertura vegetal tipo E: montaña degradada de bosque caduco bajo con arbustos caducos seco según el NDVI 0,260 - 0,319, hubo un área de mayor extensión de 53,17 $\mathrm{km}^{2}$ en el 2000, disminuyendo progresivamente al 2004 a 35,45 km², observándose un incremento a 66,17 km² el 2014. Contrariamente la cobertura vegetal tipo F: suelo agrícola según el NDVI 0,320- 0,379, hubo un área de extensión menor de 23,86 km² en el 2000, observándose una variabilidad en los años siguientes para luego incrementarse significativamente el 2014 a 34,84 km². Otros tipos de vegetación también tienen una ligera variabilidad similar, como es el tipo H: prado andino con bosque de hoja perenne, según el NDVI 0,440 - 0,499, donde se observa un área de extensión menor de $0,24 \mathrm{~km}^{2}$ en el 2000 y una variabilidad en los años siguientes para luego incrementarse significativamente el 2014 a un máximo de 0,51 km². Esto nos indica que del 2008 al 2013 las áreas de vegetación varían en esta estación del año, pero manteniendo a incrementar la vegetación de suelo agrícola y bosque de hoja ancha y perenne a las riveras del rio Niño Yucaes.

En la estación de primavera (época seca), según las figuras 3 al 9 se observan que la cobertura vegetal tipo D: bosque caduco seco estacional tropical según el NDVI 0,200 - 0,259, hubo un área de mayor extensión de $65,38 \mathrm{~km}^{2}$ en el 2000, disminuyendo progresivamente al 2014 a 57,22 $\mathrm{km}^{2}$. Contrariamente la cobertura vegetal tipo F: suelo agrícola según el NDVI 0,320- 0,379 hubo un área de extensión menor de 4,97 $\mathrm{km}^{2}$ en el 2000, incrementarse significativamente el 2014 a 21,09 km². Otros tipos de vegetación también tienen una ligera variabilidad similar, como es el tipo E: montaña degradada de bosques caduco bajo con arbustos caducos, según el NDVI 0,260 - 0,319 donde se observa un área de extensión mediana de $30,17 \mathrm{~km}^{2}$ en el 2000 y una variabilidad en los años siguientes para luego incrementarse significativamente el 2012 a un máximo de 77,35 km², teniendo un descenso al 2014 de $57,41 \mathrm{~km}^{2}$. Esto nos indica que del 2000 al 2012, las áreas de vegetación en esta estación del año varían, porque en dicha zona de estudio empiezan la época de cosecha, pero manteniéndose un incrementar ligero la vegetación de suelo agrícola y bosque de hoja ancha y perenne a las riveras del rio Niño Yucaes.

\section{VALIDACIÓN DE DATOS DE IMÁGENES SATELITALES SEGÚN NDVI, PRECIPITACIÓN ATMOSFÉRICA.}


Figura 10: Relación entre NDVI y precipitación atmosférica

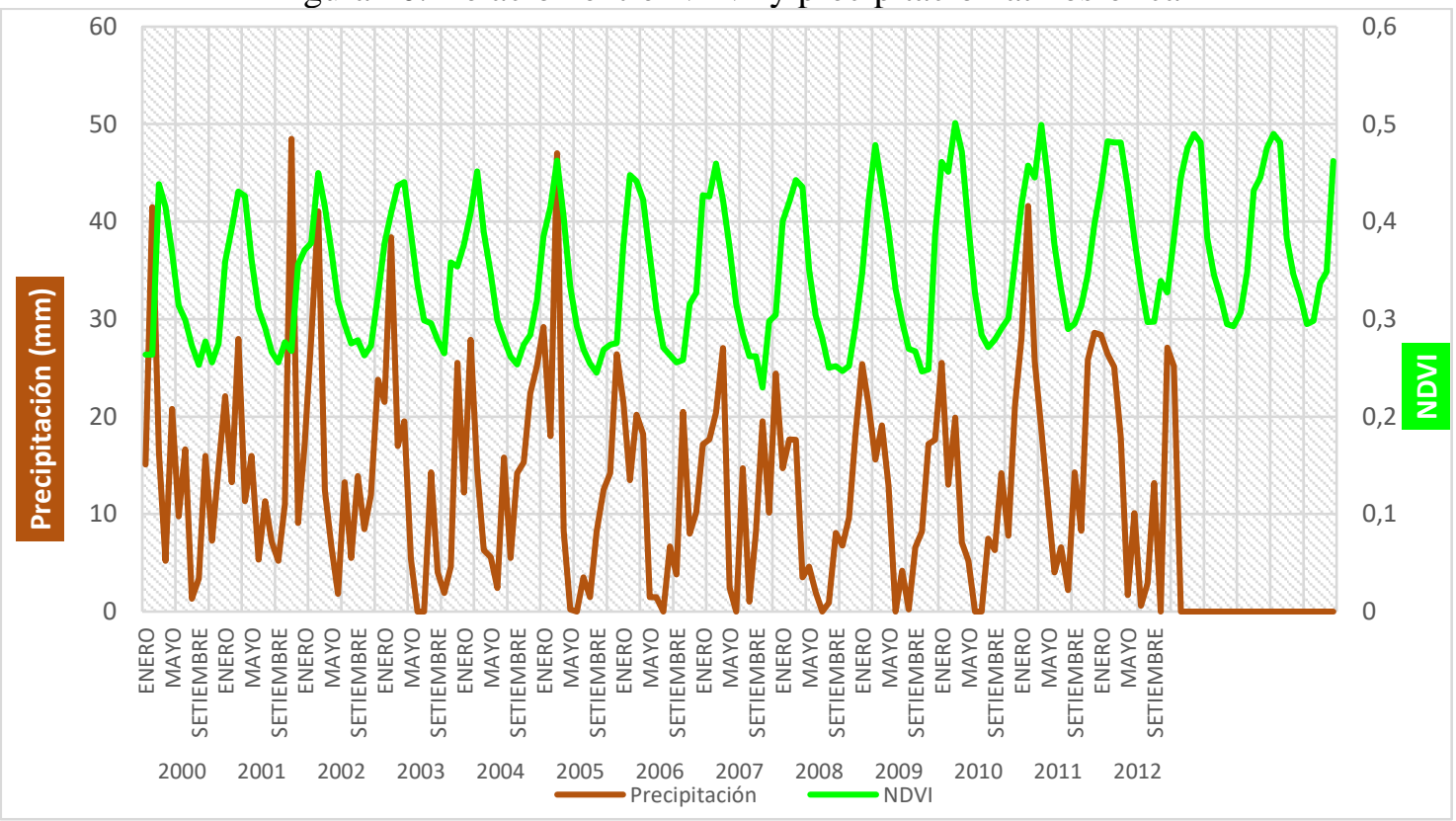

Se muestra la relación estadística descriptiva en series de tiempo del NDVI y la precipitación atmosférica máxima, donde se observa una máxima precipitación atmosférica promedio entre diciembre, enero y febrero (intensas lluvias), en los meses de marzo abril y mayo observamos suelos agrícolas con una máxima cobertura vegetal.

La validación del NDVI con respecto a la precipitación que se muestra en la figura 10 muestra la relación estadística en series de tiempo sobre las precipitaciones máximas y el NDVI, como resultado se observa que al tener una máxima precipitación promedio entre diciembre, enero y febrero (intensas lluvias), en el mes de marzo abril y mayo observamos suelos agrícolas con una máxima cobertura vegetal 
Figura 11: Relación entre NDVI y la temperatura atmosférica

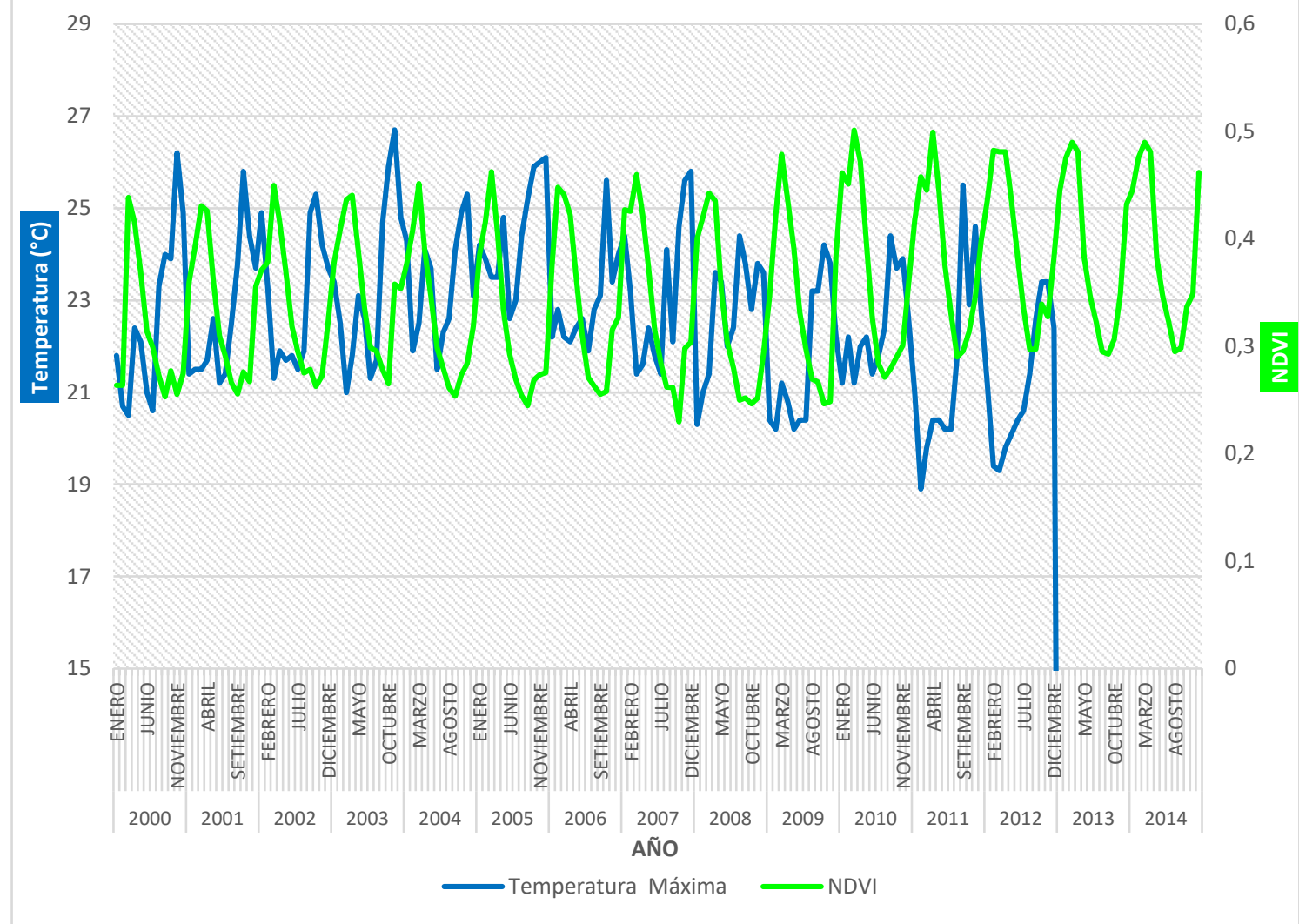

Se muestra del mismo modo la relación estadística descriptiva en series de tiempo sobre el NDVI y la temperatura atmosférica máxima. Observamos que, al tener una máxima temperatura atmosférica en promedio entre los meses de agosto, setiembre, octubre y noviembre, se tiene un mínimo de NDVI en estos mismos meses. Un aumento de la temperatura atmosférica hace que disminuya áreas de los suelos agrícolas.

\section{VALIDACIÓN DE DATOS DE IMÁGENES SATELITALES SEGÚN NDVI Y TEMPERATURA ATMOSFÉRICA.}

Así mismo, la figura 11 muestra la relación estadística en series de tiempo sobre la temperatura máximas y el NDVI. Observamos que, al tener una mayor temperatura en promedio entre los meses de agosto, setiembre, octubre y noviembre, se tiene un valor menor de NDVI en estos mismos meses. La consecuencia del aumento de la temperatura del aire hace que disminuya el área de los suelos agrícolas.

Los estudios de los mapas temáticos de la Zonificación Ecológica y Económica (ZEE -2012) publicados por el Gobierno Regional de Ayacucho sustentan dichos resultados.

Finalmente, y en conclusión se puede manifestar que se logró describir el comportamiento del Índice de Vegetación de Diferencia Normalizada con las 341 imágenes (MOD13Q1) según estaciones del 
año en $\mathrm{km}^{2}$ y tipos de cobertura vegetal de suelos en series de tiempo, como muestra los resultados de las figuras 1 al 9, alcanzando así uno de los objetivos específicos propuestos.

Las figuras 10 y 11 nos permitió estimar y validar los resultados obtenidos del Índice de Vegetación de Diferencia Normalizada y datos de precipitación y temperatura atmosférica de la estación meteorológica de Tambillo, en el periodo 2000-2014 obteniendo así el objetivo específico propuesto.

Se logró evaluar el impacto de uso de suelos según el Índice de Vegetación de Diferencia Normalizada en series de tiempo, durante el periodo 2000 al 2014 con información generada por las imágenes satelitales MODIS Terra del distrito de Tambillo, como muestra la figura 1, logrando así el objetivo general planteado.

Se determinó un aumento en las áreas de cobertura vegetal, lo que causó una disminución en áreas de zonas de suelo desnudo, lo cual es satisfactorio debido a que indica la mejora en el comportamiento fenológico de la vegetación en el distrito de Tambillo como resultado de las actividades propuestas en el plan anual de manejo de áreas de cultivo por las entidades pertenecientes al Gobierno Regional de Ayacucho (irrigación por aguas del proyecto especial rio Cachi), negando así la hipótesis nula planteada y aceptándose la hipótesis alterna, tales resultados se muestran en las figuras 6 al 9. 


\section{REFERENCIAS BIBLIOGRÁFICAS}

[1] CARVACHO BART, L. y SÁNCHEZ MARTÍNEZ, M. Comparación de índices de vegetación a partir de imágenes MODIS en la región del Libertador Bernardo O’Higgins, Chile; en el período 2001-2005. En: Ojeda, J., Pita, M.F. y Vallejo, I. (Eds.) Tecnologías de la Información Geográfica: La Información Geográfica al servicio de los ciudadanos. Secretariado de Publicaciones de la Universidad de Sevilla; 2010. ISBN 978-84-472-1294-1:728-737.

[2] FUMING WANG; JINGFENG HUANG y LA CHEN. Development of a vegetation index for estimation of leaf area index based on simulation modeling. Journal of Plant Nutrition; 08 enero 2010, vol. 33. $\mathrm{N}^{\circ} 3$ p. $328-338$.

[3] SANCHA NAVARRO, E.F. El estudio de los índices de vegetación como base para conocer las relaciones entre la vegetación y el clima. Publicaciones de la Universidad de Sevilla. (Sevilla); 2010. ISBN: 978-84-472-1294-1:95-108.

[4] RABAGLIO, M. Impacto del uso del suelo sobre el Índice de Vegetación Normalizado. [Tesis pre grado]. La Plata: Universidad de Buenos Aires; 7 junio 2012.

[5] MATTAR C., SOBRINO J. A., WIGNERON. J. P., JIMÉNEZ-MUÑOZ J. C y KERR. Y. Estimación de la humedad del suelo a partir de índices de vegetación y microondas pasivas. Revista de Teledetección. Asociación Española de Teledetección; 2011. vol.36. ISSN: 1988-8740, 62-72.

[6] ABAURREA PEREDA, M. Comparación de índices de vegetación en zona semiárida de Navarra [Tesis pre grado]. España, Universidad Pública de Navarra; setiembre 2013.

[7] GONZALES AGUILAR. C. Aplicación del Índice de Vegetación Derivados de la Imagen. [Tesis de maestría]. Ecuador. Universidad Nacional de la Plata; 08 abril 2014.

[8] ALBURQUEQUE. S y ROJAS. A. Estimación de la Temperatura Superficial del Mar Peruano Usando Imágenes AVHRR y MODIS en el Infrarrojo Térmico-2008. Dirigido por Universidad Nacional Mayor de San Marcos, Facultad de Ciencias Físicas, Lima-Perú. Trabajo ha sido financiado por la UNMSM en el año 2009 y por programa. INCAGRO del Ministerio de Agricultura en los años 2007-2009; 2010.

[9] QUEZADA. G y ROJAS. A. Modelo físico de la estimación de la concentración de clorofila-a en el mar peruano usando imágenes MODIS. Revista de Investigación de Física. Universidad Nacional Mayor de San Marcos, Facultad de Ciencias Físicas, Lima-Perú; 28 diciembre 2011, vol. 4, 111402403.

[10] MONCADA, W. MASÍAS, M. ALDANA, C. PAIVA, D. Mapeo de nubosidades en la región Ayacucho mediante sistema satelital, 2000 al 2010. En: Revista de Investigación de la Universidad Nacional San Cristóbal de Huamanga; 2011.

[11] SOLANO. R y ROJAS. A. Evaluación de la vegetación y del estado de suelos de la Región Ayacucho mediante datos satelitales, periodo 2000 - 2012”, dirigido por la Universidad Nacional San Cristóbal de Huamanga, Ayacucho. Financiamiento: Fondo de Desarrollo Socioeconómico del Proyecto Camisea (FOCAM); 2013.

[12] MONCADA W. JIMENEZ J. PEREDA A. ALDANA C. Cuantificación hidrográfica de la cuenca del Rio Cachi Ayacucho, mediante imágenes satelitales Revista de Investigación de la Universidad Nacional San Cristóbal de Huamanga; 2014. 
[13] CHUVIECO, E y HUETE, A. Fundamentals of Satellite Remote Sensing. [Libro]. New York, 2010: Taylor y Fransis group, [27/04/2016].

Disponible en: https://www.crcpress.com/Fundamentals-of-Satellite.

[14] RODRIGUEZ, P., SANCHEZ, C. y DOMINGUEZ, G. Cuestiones de Teledetección, edición digital. Universidad Nacional de educación a distancia. [Libro]. Madrid, España, 2015: UNED, [12/0972015]. Disponible en: ISBN electrónico: 978-84-362-7067-9 edición digital.

[15] MARTÍN EDROSA, R Aplicación de la teledetección para el monitoreo de eventos hídricos superficiales mediante imágenes cosmo sky med. [Tesis de maestría] Córdoba, Argentina. Universidad Nacional de Córdova. Julio 2011.

[16] ARBELO MANUEL. Teledetección, tutorial. [Texto tutorial]. Universidad de La Laguna España.Editorial John Willey \& Sons. [27/04/2016].

Disponible en: https://marbelo.webs.ull.es/rs.html.

[17] FRANCOIS, J; TZITZIKI, J. LOPEZ, G; COLDITZ. Aplicaciones del Sensor MODIS para el Monitoreo del Territorio. Secretaría de Medio Ambiente y Recursos Naturales. Primera edición. Universidad Nacional Autónoma de México, Printed; 2011.

[18] LOPEZ GARCIA, B. Estudio comparativo de índices espectrales aplicados a los incendios del Alt Empordá de 2000 y 2012 a través de imágenes MODIS [Tesis ingeniería técnica topográfica]. Universidad Politécnica de Catalunya. Enero/febrero 2013.

[19] COLDITZ, R.R. Time series generation and classification of MODIS data for land cover mapping. Dissertation. IEEE Transactions on Geoscience and Remote Sensing; octubre 2008, vol. 46, No 10, 3308.

[20] MUÑOZ AGUAYO, P. Índice de Vegetación Diferencial Normalizado. [Tesis maestría]. Departamento Provincial de Aguas de Argentina. Geógrafo CIREN; 2015. Disponible en: https://www.agroclimatico.minagri.gob.cl/.../2015/.../Indices-de-vegetación-Pedro-Muñoz.

[21] TRANSPORTADORA DE GAS DEL PERÚ S.A. Uso actual de la tierra Ayacucho: informe de INRENA en 1999 para PRONAMACHCS: TGP; 13 de enero 2014. Disponible en: http://www.southperupanel.org/files/eias/04.\%20EIA\%20MODIFICACIONES\%20TRANSPORTE\%20 PRODUCTOS/Volumen\%20II\%20\%20LB\%20Amb\%20y\%20Soc/1.2\%20L\%C3\%ADnea\%20Base $\% 2$ 0Ayacucho/1.2.7\%20Uso\%20Actual.doc.

[22] GOBIERNO REGIONAL DE AYACUCHO. Zonificación Ecológica Económica de la región de Ayacucho. Documento: Memoria Descriptiva de Cobertura Vegetal y Uso Actual-ZEE del departamento Ayacucho-Perú; 2012.

[23] USGS MODIS reprojection tool web interface (MRTWeb), consultado del 25 de agosto de 2013 hasta 27 de abril del 2016. http://mrtweb.cr.usgs.gov. 2010.

[24] WATANABE, J. Manejo del ENVI 4,5 [Monografía en internet]. Cajamarca-Perú; 09 de noviembre del 2010.

Disponible en: http://www.monografias.com/trabajos82/manejo-envi/manejo-envi5.shtml. 
[25] FAO. Evaluación de los recursos forestales mundiales 2010. Informe nacional Perú. FRA2010/163 Roma.2010.

Disponible en: www.fao.org/forestry/20416-076b3fb72d387f4ce89a10d2cc71194d.pdf. 